\title{
A SEXUALIDADE NA ETIOLOGIA DAS NEUROSES E A INVENÇÃO DA PSICANÁLISE
}

\section{Márcio Aparecido Mariguela}

\section{RESUMO}

Em 1917, Freud definiu a sexualidade como tudo o que se relaciona com a distinção entre os dois sexos. Dessa premissa, extraiu uma conclusão: aquilo que é sexual é da ordem do impróprio. Minha estratégia nesse artigo é retornar à hipótese da sexualidade infantil para demarcar a invenção da psicanálise como arte da escuta desse algo impróprio que deve ser mantido secreto. Proponho uma leitura do artigo “A hereditariedade e a etiologia das neuroses”, escrito em francês e publicado por Freud em 1896, para demarcar a criação da psicanálise pela ruptura que estabeleceu com o discurso neurológico sobre os sintomas das psiconeuroses. Na seqüência, destaco alguns argumentos que se encontram no artigo "A sexualidade na etiologia das neuroses”, publicado em 1898, por considerálo o ponto de passagem para a publicação da obra fundadora da psicanálise: A Interpretação dos Sonhos. O primeiro artigo demonstra um ponto de ruptura; o segundo um ponto de passagem para que Freud pudesse instaurar as bases conceituais da teoria e da prática psicanalítica.

\section{PALAVRAS-CHAVE}

História da psicanálise; Etiologia das neuroses; Sexualidade infantil

\section{THE ROLE OF SEXUALITY IN THE ETIOLOGY OF NEUROSES AND THE INVENTION OF PSYCHOANALYSIS}

\begin{abstract}
In 1917, Freud defined sexuality as everything related to the distinction between the two sexes, getting to the conclusion that everything which is sexual is improper. My strategy in writing this article is to return to the hypothesis of child sexuality, marking it as a date to the invention of psychoanalysis as the art of listening to this improper something which should be kept in secret. I proposed the, "The heredity and the etiology of the neuroses", written in French and published by Freud in 1896, as a date to the creation of psychoanalysis for the rupture it settled by the use of neurological discourse about the symptoms of the psychoneurosis.By addition, I highlight some arguments found in the "The sexuality in the etiology of neuroses", published in 1898, for I consider it as the point of passage to the publication of the witting which founded psychoanalysis: The interpretation of dreams. The first writing demonstrates a point of change, while the second, a point of passage so that Freud could set the conceptual basis of the theory and practice of psychoanalysis.
\end{abstract}

\section{KEYWORDS}

History of psychoanalysis; Etiology of neurosis; Child sexuality 


\section{INTRODUÇÃO}

Freud iniciou sua Conferência XX , de 1917, fazendo uma descrição da vida sexual dos seres falantes. Para tanto, definiu o conceito de sexual como sendo "tudo o que se relaciona com a distinção entre os dois sexos". Dessa premissa, extraiu uma conclusão: aquilo que é sexual é da ordem do impróprio. Assim, sexual é "algo que reúne uma referência ao contraste entre os sexos, à busca de prazer, à função reprodutora e às características de algo que é impróprio e deve ser mantido secreto" (FREUD, 1976b, p.356). O propósito deste artigo é argumentar que a impossibilidade de representação psíquica da diferença anatômica entre os sexos é esse “algo impróprio” que define o sexual. Para tanto, pretendo demarcar um ponto de ruptura entre o discurso neurológico sobre os fenômenos histéricos e o discurso psicanalítico inaugurado por Freud em dois artigos que considero de relevante importância para analisar a emergência histórica da psicanálise.

Desse modo, desejo brindar o nascimento do homem Freud e ato contínuo saudar sua nobre invenção: a psicanálise. O homem Freud criou um campo discursivo que permitiu interrogar a experiência da loucura em novas bases conceituais. É, pois, como instaurador de discursividade, que o nome Freud inscreve-se numa função autor da psicanálise. ${ }^{1}$ Ele instaurou um discurso que confrontou o pensamento contemporâneo rompendo as fronteiras entre o normal e o patológico, estabelecida pelo discurso neurológico e pela prática psiquiátrica. Ao definir o sexual como da ordem do impróprio, Freud abriu uma nova possibilidade de interrogar a sexualidade para além do discurso biológico. De igual modo, constatou o esforço que é feito historicamente para manter esse impróprio recalcado pela moral.

\footnotetext{
${ }^{1}$ A premissa assumida neste artigo foi retirada da posição de Foucault na conferência “O que é um autor?”, proferida na Sociedade Francesa de Filosofia em 1969. Na última parte de sua comunicação, Foucault aplicou seus enunciados sobre a função autor a um determinado campo (ou unidade) discursivo. Para tanto, interrogou a legitimidade do autor na fundação de uma disciplina, o significado do movimento de retorno a... e as transformações que tal retorno opera no campo discursivo em questão. Freud e Marx foram eleitos como exemplares para investigar a função autor: considerou ambos como fundadores de discursividade e, desse modo, ocuparam uma posição transdiscursiva na história efetiva dos saberes contemporâneos. (in: FOUCAULT, 2001)
} 
Em sua Conferência $X X$, Freud fez referências à arte pictórica de Breughel e à obra A tentação de Santo Antônio, escrita por Gustave Flaubert e, publicada 1849. Essas referências serviram como uma boa metáfora para Freud introduzir o tema da perversão para designar o impróprio que define a vida sexual dos seres humanos: "Na sua multiplicidade e estranheza, somente podem ser comparadas aos monstros grotescos, pintados por Breughel para a tentação de Santo Antonio, ou à longa procissão de deuses e crentes desaparecidos, que Flaubert faz desfilar ante os olhos do piedoso penitente" (FREUD, 1976b, p.357). Uma série foi construída por Freud para agrupar a classe dos pervertidos, pois, frente a "uma tal miscelânea requer algum tipo de ordenamento para que não venham confundir nossos sentidos” (FREUD, 1976b, p.357). Toda uma tipologia das perversões aparece no ordenamento apresentado por Freud. Em cada grupo um tipo específico que, no conjunto, representa um fenômeno que interroga as fronteiras entre o normal e o patológico. Através da escuta clínica dos pacientes neuróticos [histeria e obsessão], Freud constatou a existência de

\begin{abstract}
grupos de indivíduos cuja vida sexual se desvia, da maneira mais surpreendente, do quadro habitual da média (...) e devemos nos lembrar de que cada um destes grupos podem ser encontrados sob duas formas: ao lado daqueles que procuram sua satisfação sexual na realidade, estão os que se contentam simplesmente com imaginar essa satisfação, que absolutamente não necessitam de um objeto real, mas podem substituí-lo por suas fantasias. (FREUD, 1976b, pp. 356 e 358 itálico do autor)
\end{abstract}

Este argumento apresentado em 1917 remete à tese da sexualidade infantil, que emergiu em 1905 nos Três Ensaios sobre a Teoria da Sexualidade. No primeiro ensaio Freud caracterizou as aberrações sexuais em duas classes: os desvios com respeito ao objeto sexual; e os desvios com respeito ao alvo sexual. Ao final, identificou a pulsão sexual nos neuróticos em sua experiência clínica de aproximadamente vinte e cinco anos e, a partir de sua definição de pulsão estabeleceu duas premissas fundamentais: "os sintomas são a atividade sexual dos doentes (...) os sintomas representam um substituto de aspirações que atraem sua força da fonte da pulsão sexual” (FREUD, 1989, pp.153 e 154).

Freud reconheceu que tal premissa atraiu boa parte da oposição contra sua tese da 
sexualidade infantil. ${ }^{2}$ Os adversários da psicanálise não admitiam [será que ainda admitem?] o pressuposto elementar que justificava sua tese: a pulsão sexual que atua nas psiconeuroses é a mesma que atua nas pessoas que se consideram normais. A psicanálise ensina que "os sintomas se formam, em parte, às expensas da sexualidade anormal" e que os mesmos "representam a expressão convertida de pulsões que seriam designadas de perversas (no sentido mais lato) se pudessem expressar-se diretamente, sem desvio pela consciência, em propósitos da fantasia e em ações”. Desse ensinamento extraiu a seguinte conclusão: a neurose é, por assim dizer, o negativo da perversão (FREUD, 1989, p.155 itálico do autor).

A pulsão sexual dos psiconeuróticos permite discernir todas as aberrações que estudamos como variações da vida sexual normal e como manifestações da patológica. a) na vida psíquica de todos os neuróticos (sem exceção) encontramse moções de inversão, de fixação da libido em pessoas do mesmo sexo (...) b) no inconsciente dos psiconeuróticos é possível demonstrar, como formadoras do sintoma, todas as tendências à transgressão anatômica (...) c) um papel muito destacado entre os formadores de sintomas das psiconeuroses é desempenhado pelas pulsões parciais [destaca-se que esta é a primeira aparição desse conceito na obra de Freud], que na maioria das vezes aparecem como parte de opostos [exibicionismo-voyerismo; sadismo-masoquismo, por exemplo]. (FREUD, 1989, p.156)

Doravante, a indicação do infantilismo da sexualidade se impõe de forma determinante, na demarcação do campo discursivo da psicanálise, pois, "ao demonstrar as moções perversas enquanto formadoras de sintomas nas psiconeuroses, aumentamos extraordinariamente o número de seres humanos que poderiam ser considerados perversos” (FREUD, 1989, p.157). É por isso que a extraordinária difusão das perversões levou Freud a suposição de que a perversão é constitutiva da sexualidade considerada até então como normal, ou seja, tal como enunciada pelo discurso biológico. Dessa forma, a sexualidade infantil, concebida como polimorfa e perversa, invadiu o discurso da normalidade e a longa procissão de anormais desfila como deuses e crentes desaparecidos.

\footnotetext{
${ }^{2}$ Freud iniciou a "Conferência XXI - O desenvoilvimento da libido e as organizações sexuais” afirmando que o tema das perversões era uma estratégia interessante para modificar o conceito de sexualidade. Romper com a concepção biológica que definia a natureza sexual pela função reprodutora era uma tarefa imprescindível para edificar a psicanálise à partir do estudo da sexualidade infantil. Considerou que não foi sua estratégia que produziu uma aversão histórica a psicanálise e sim seus argumentos sobre a sexualidade infantil: "O estudo da sexualidade infantil teve muito mais influência sobre esse fato [objeções à psicanálise], e foi o concurso
} 
Minha estratégia nesse artigo é retornar à hipótese da sexualidade infantil para sustentar a invenção da psicanálise como arte da escuta desse algo impróprio que deve ser mantido secreto. Proponho uma leitura do artigo "A hereditariedade e a etiologia das neuroses” (1994), escrito em francês e publicado por Freud em 1896, para demarcar a criação da psicanálise pela ruptura que estabeleceu com o discurso neurológico sobre os sintomas das neuroses, em específico, a neurose histérica. Na seqüência, destaco alguns argumentos que se encontram no artigo “A sexualidade na etiologia das neuroses” (1994), publicado em 1898, por considerá-lo o ponto de passagem para a publicação de sua obra fundadora: A Interpretação dos Sonhos. O primeiro artigo demonstra um ponto de ruptura; o segundo, um ponto de passagem para que Freud pudesse instaurar as bases conceituais da teoria e da prática psicanalítica.

\section{A DEMARCAÇÃo DA NEUROSE HISTÉRICA NA NEUROLOGIA DE CHARCOT}

Antes de publicar a Interpretação dos Sonhos, considerada a pedra angular da psicanálise, Freud escreveu diversos artigos, resenhas e verbetes para enciclopédia, demarcando seu campo de saber frente à polifonia científica de seu tempo. Publicou em 1891 um estudo Sobre a concepção das Afasias, seu primeiro livro. Traduziu também as aulas de Jean-Martin Charcot e algumas proposições de Jonh Stuart Mill. Escreveu sobre a paralisia cerebral infantil e um controvertido trabalho sobre o uso anestésico da cocaína. Manteve correspondência assídua com Wilhelm Fliess, o parteiro da psicanálise, que foi o primeiro a receber um exemplar impresso do livro dos sonhos como presente de aniversário.

Assinou ainda, com Josef Breuer, em abril de 1895, a edição do livro Estudos sobre a Histeria, no qual sustentou pela primeira vez sua hipótese de que a sexualidade desempenha "um papel fundamental na patogênese da histeria, como fonte de traumas psíquicos e como motivação para a 'defesa' - isto é, para que as idéias sejam recalcadas da 
consciência" (FREUD,1995, p.33). No entanto, esta hipótese não pôde ser demonstrada, pois as observações de natureza marcadamente sexual não foram publicadas por decisão expressa dos autores. No prefácio à primeira edição dessa obra, Freud estabeleceu o campo de sua experiência clínica, através do uso do método hipnótico, e os motivos que levaram à decisão de não publicar as observações que revelavam as representações de natureza sexual:

Nossa experiência provém da clínica particular numa classe social culta e letrada, e o assunto com que lidamos muitas vezes aborda a vida e a história mais íntimas de nossos pacientes. Constituiria grave quebra de confiança publicar material dessa espécie, com o risco de os pacientes serem identificados, e seus conhecidos ficarem a par de fatos confiados apenas ao médico. (FREUD, 1995, p.33)

Entre os Estudos sobre a Histeria de 1895 e a Interpretação dos Sonhos de 1900, há um percurso constitutivo para a edificação dos alicerces da psicanálise. $\mathrm{O}$ fator sexual como agente etiológico das psiconeuroses mantém-se como eixo em torno do qual giram os registros da prática clínica e das elaborações teóricas de Freud. Tendo como referência o livro Estudos sobre Histeria, podemos avaliar a demarcação do campo da psicanálise pela eleição de um objeto de estudo: a histeria. É sabido que o quadro sintomatológico da histeria recebeu sua configuração no discurso neurológico. No discurso da ciência neurológica a histeria foi interrogada pelo célebre Dr. Jean-Martin Charcot. Portanto, os chamados "fenômenos histéricos", emergem no discurso médico na segunda metade do século XIX: quer seja para negativar a histeria como doença, quer para afirmá-la como decorrente de um trauma psíquico.

Tendo como propósito estabelecer a causalidade etiológica dos sintomas histéricos, o discurso da ciência neurológica teve de se confrontar com os argumentos dos médicos que negavam à histeria o estatuto de doença. $\mathrm{O}$ argumento para tal posição estava fundado no fato de que os fenômenos histéricos não tinham causalidade orgânica. As histéricas fingiam, dissimulavam, encenavam um sofrimento que não tinha justificativa científica que pudesse explicar aquilo que os pacientes relatavam como sofrimento. Afastado o pressuposto de causalidade orgânica para explicar a etiologia da histeria, restava apenas sustentar uma causalidade psíquica. Mas, neste caso, a ciência médica entraria no campo

para nós” (FREUD, 1976b, p. 375).

(C) ETD - Educação Temática Digital, Campinas, v.8, n.esp., p.169-186, dez. 2006 - ISSN:1676-2592. 
das explicações psicológicas. Como demarcar as fronteiras entre a doença mental e a doença orgânica? ${ }^{3}$.

A neurologia era a seara da medicina mental. Freud, por exemplo, iniciou seus estudos em neurologia sob orientação de Franz Scholz. Sua pesquisa estava centrada no nervo acústico e o resultado foi publicado em 1886, com o título: "Sobre a origem do nervo acústico". No mesmo período, recebeu uma bolsa de estudos da Universidade de Viena para uma estada em Paris, onde conheceu Charcot, o médico francês que dirigia o Hospital Salpêtrière ${ }^{4}$, considerado a Meca dos neurologistas interessados em pesquisar as doenças dos nervos em geral e a histeria em particular.

Vale lembrar que Charcot publicou em 1873 um instigante livro intitulado: Lições sobre as doenças do sistema nervoso - livro esse que Freud traduziu para o alemão. Outro fato revelador da importância da neurologia foi a criação da primeira cátedra de "doenças nervosas" da Europa em janeiro de 1882. Charcot foi nomeado seu titular. Pela primeira vez na história, a neurologia foi reconhecida como disciplina autônoma no reino da fisiologia. No mesmo ano, Charcot proferiu uma conferência na Academia de Ciências da França onde apresentou os argumentos para conceber os fenômenos histéricos como uma doença dos nervos. Estava aberta assim, a possibilidade de pensar a histeria como uma neurose de origem traumática. A noção de trauma psíquico permitiu que Charcot isolasse um grupo de sintomas caracterizados como histeria. Trauma era compreendido como uma representação contrastante entre um evento físico e sua significação psíquica.

Charcot conseguiu desvincular a neurose ${ }^{5}$ do campo da doença orgânica. Se a histeria é uma neurose, sua nosografia pôde ser traçada pela demarcação de um achado clínico de Charchot: o sintoma histérico é a encarnação de um trauma psíquico. A questão decorrente dessa premissa consiste em compreender essas representações contrastantes e

\footnotetext{
${ }^{3}$ Na "Introdução" de seu livro Doença Mental e Psicologia, reeditado em 1962, Michel Foucault demarcou com precisão o problema que estava em questão: "sob que condições pode-se falar de doença no domínio psicológico? Que relações podem definir-se entre os fatos da patologia mental e da patologia orgânica? (...) Se parece tão difícil definir a doença e a saúde psicológicas, não é porque se tenta em vão aplicar-lhes maciçamente conceitos destinados igualmente à medicina somática?”. (FOUCAULT, 1984, p.7)

${ }^{4}$ Hospital Salpêtrière era uma antiga fábrica de pólvora construída no reinado de Luis XIV que durante muito tempo foi o maior Hospital da Europa, chegando a ter uma população de cinco a oito mil pessoas. Outra curiosidade: o Dr. Charcot foi o médico de D.Pedro II.

${ }^{5}$ conceito criado pelo médico escocês W.Cullen em 1777 para designar as afecções mentais
} 
permitir algum tipo de alívio para o sofrimento dos pacientes histéricos. Ocorre, no entanto, que a técnica terapêutica disponível para chegar às causas traumáticas da histeria era exercida pelo ato hipnótico. Sob efeito do ato hipnótico, os pacientes eram conduzidos na busca dessa situação traumática originária.

É sabido das dificuldades de Freud em utilizar o método hipnótico em seu início do trabalho clínico. Aos impasses de Freud, suas histéricas auxiliaram na formulação do método de associação livre: ato fundador da escuta psicanalítica. Ao nomear como psicanálise sua prática clínica, Freud instituiu um campo de saber sobre a neurose histérica e passou a incluir nesse campo, a neurose obsessiva. Este ato de nomeação foi realizado no único artigo que Freud escreveu em francês: “A hereditariedade e a etiologia das neuroses”. Publicado em 1896, na Revue de Neurologie, o artigo inicia com a indicação do destinatário: "Dirijo-me em particular aos discípulos de J.M. Charcot, para formular algumas objeções à teoria etiológica que nos foi legada pelo nosso mestre”. (FREUD, 1994, p.143)

\section{FREUD E A SITUAÇÃO FRANCESA: O ATO DE NOMEAÇÃO DA PSICANÁLISE}

Em 1926, Freud publicou o verbete Psicanálise (1976a) na décima terceira edição da Encyclopaedia Britannica. Nele, apresentou um resumo histórico da criação da psicanálise, desde as descobertas de Josef Breuer, oriundas da aplicação do método catártico, até a situação naquele ano. Considero esse verbete um registro histórico de grande valor. Ao descrever a "Pré-História” da psicanálise, Freud indicou seu trabalho com Josef Breuer como ponto de partida para constituição da psicanálise e afirmou que esse trabalho nada deve às investigações de Jean-Martin Charcot e de Pierre Janet sobre a origem dos sintomas histéricos. Aqui encontramos a demarcação de uma posição em relação àquilo que Freud aprendeu com o seu mestre Charcot, no período de sua residência médica na Salpêtrère de Paris em 1886. Quarenta anos se passaram desde que Freud foi ao encontro das histéricas na clínica do Dr. Charcot. Tempo que rememorado permitiu Freud estabelecer dois significados para a palavra psicanálise: “um método específico de tratar as 
perturbações nervosas e, a ciência dos processos psíquicos inconscientes, que também é apropriadamente descrita como 'psicologia profunda'” (FREUD, 1976a, p.302).

Após demarcar o contorno do campo da psicanálise, Freud afirmou:

a influência terapêutica da psicanálise depende da substituição de atos mentais [psíquicos] inconscientes por conscientes e vigora dentro dos limites desse fator. A substituição é efetivada superando-se as resistências internas na mente do paciente. O futuro provavelmente atribuirá muito maior importância à psicanálise como ciência do inconsciente do que como um procedimento terapêutico. (FREUD, 1976a, p.302)

O verbete apresenta, ainda, três aspectos teóricos que sustentam a argumentação sobre o funcionamento psíquico e, por extensão, coordenam a prática clínica: o dinâmico, o econômico e o topográfico. Freud aproveitou para expressar sua convicção de que a "psicanálise, em seu caráter de psicologia dos atos mentais inconscientes mais profundos, promete tornar-se o elo entre a psiquiatria e todos aqueles outros ramos da ciência mental". (FREUD, 1976a, p. 307)

No final do verbete, Freud descreveu a "História Externa da Psicanálise" para indicar sua implantação nos países europeus. O crescente interesse pela psicanálise foi reconhecido por Freud pela proporcional hostilidade que produzia. A razão dessa hostilidade pode ser identificada em dois níveis:

do ponto de vista médico, no fato de que a psicanálise dá ênfase a fatores psíquicos e, do ponto de vista filosófico, na suposição do conceito de atividade mental inconsciente como sendo um postulado fundamental; mas a razão mais forte foi, indubitavelmente, a indisposição geral da humanidade em conceder ao fator da sexualidade a importância que lhe é atribuída pela psicanálise. (FREUD, 1976a, p.308)

Mesmo assim, reconheceu Freud, o movimento psicanalítico aglutinou-se e fortaleceu-se numa Associação Internacional, "que atravessou incólume as provações da Grande Guerra, e na hora presente [1926] abrange grupos locais em Viena, Berlim, Budapeste, Londres, Suíça, Holanda, Moscou e Calcutá, bem como dois nos Estados Unidos" (FREUD, 1976a, p.308). É curioso notar que não há nenhuma menção à França que, naquele momento, estava criando sua primeira Sociedade Psicanalítica. 
Como podemos observar, a referência aos franceses aparece no que Freud caracterizou como a pré-história da psicanálise. Nela, os nomes de Charcot e Janet são destacados como marcos teóricos nos estudos sobre histeria. O embate entre Freud e Janet constitui um capítulo especial de roubo de idéias que atravessou a saga da implantação da psicanálise na França.

Um indicativo desse embate pode ser encontrado no artigo "A hereditariedade e a etiologia das neuroses" (1994). Foi nesse artigo, escrito em 1896, que Freud utilizou pela primeira vez a palavra psicanálise para designar sua prática clínica. Encontra-se também, nesse trabalho, um resumo das concepções contemporâneas de Freud sobre a etiologia dos quatro tipos de neuroses que ele então considerava os principais: as duas psiconeuroses, histeria e neurose obsessiva; e as duas "neuroses atuais", neurastenia e neurose de angústia. Assim, Freud nomeou a psicanálise estabelecendo uma cartografia da neuropatologia do final do século XIX e apresentando seus resultados da pesquisa clínica sobre estes quatro tipos de neurose.

O referido artigo é um marco na história da psicanálise por dois motivos: nele, Freud estabeleceu uma ruptura no campo da psiquiatria clássica e demarcou sua empreitada na construção da teoria do inconsciente; por outro lado, ao publicá-lo em francês, o autor acertou suas dívidas para com o célebre Dr. Charcot, com quem aprendera a reconhecer o discurso histérico como enunciador da verdade psíquica.

Os argumentos do artigo revelam-nos sua extemporaneidade. As idéias principais de Freud, embora refutadas após a introdução da hipótese da sexualidade infantil, mantêm ainda sua relevância na formulação da psicanálise como prática clínica, sustentada na escuta dos sintomas da neurose histérica e neurose obsessiva - as duas neuroses que compõem o grupo de estudos de Freud. A etiologia das neuroses foi demarcada em três classes: Precondições: que são indispensáveis para produzir os distúrbios neuróticos - nessa classe é compreendido o fator hereditário; Causas Concorrentes: que compartilham com as precondições a característica de funcionarem tanto na causação de outros distúrbios quanto na dos distúrbios neuróticos, dentre elas, destacou a perturbação emocional, esgotamento físico, intoxicações, acidentes traumáticos, sobrecarga intelectual, etc; Causas Específicas: 
"que são indispensáveis como as precondições, mas têm natureza limitada e só aparecem na etiologia do distúrbio de que são específicas”. (FREUD, 1994, p.146)

Foi abordando as causas específicas que Freud estabeleceu a ruptura com o discurso da neuropatologia de seu tempo. Para ele, a classe das causas específicas possui uma fonte comum de onde derivam suas manifestações fenomênicas: a vida sexual do sujeito. Traçar o histórico dessa vida sexual, retroativamente dos distúrbios atuais até uma experiência sexual passiva antes da puberdade, era a proposta do método clínico da psicanálise de Freud.

\begin{abstract}
Os distúrbios sexuais sempre foram admitidos entre as causas da doença nervosa, mas têm sido subordinados à hereditariedade e coordenados com os demais agents provocateures; sua influência etiológica tem-se restringido a um número limitado de casos observados. (...) O que confere um caráter distintivo a minha linha de abordagem é que elevo essas influências sexuais à categoria de causas específicas, reconheço sua atuação em todos os casos de neurose e, finalmente, traço um paralelismo regular, prova de uma relação etiológica especial, entre a natureza da influência sexual e a espécie patológica da neurose. Estou certo de que essa teoria invocará uma tempestade de contestações por parte dos médicos contemporâneos. (FREUD, 1994, p.149)
\end{abstract}

É fato histórico que a teoria da sexualidade como fator etiológico das psiconeuroses invocou uma tempestade de contestações. Sobre Freud pesou a pecha de pansexualista. Mesmo assim, a psicanálise praticada por Freud despertou grande interesse de centenas de médicos de toda a Europa e da América do Norte. A Viena da belle époque ${ }^{6}$ recebeu um grande fluxo de pensadores liberais que procuravam aprender a prática psicanalítica com o Dr. Freud. Alguns se tornaram amigos íntimos e colaboradores; outros, discípulos, ou mesmo adversários.

\title{
FATORES EMERGENTES DA VIDA SEXUAL
}

Numa carta de 09 de fevereiro de 1898, Freud escreveu ao seu amigo Fliess que havia terminado o artigo “A sexualidade na etiologia das neurouroses” (1994). Encontra-se nesta carta a seguinte descrição que demonstra o cenário e a importância desse artigo:

\footnotetext{
${ }^{6}$ Carl SCHORSKE (1988) apresentou em seu livro, Viena fin-de-sciècle - política e cultura, elementos singulares para designar a cena austríaca na virada do século e a migração dos médicos psiquiátricos que desejavam aprender a teoria e a técnica da psicanálise.
} 
Terminei o artigo do Gartenlaube. ${ }^{7}$ É bastante impertinente e essencialmente feito para insultar, no que sem dúvida terá êxito. Breuer dirá que causei mais prejuízos a mim mesmo. Corre um boato de que estou prestes a ser investido com o título de professor, no jubileu do imperador, a 2 de dezembro. Não creio nisso, mas tive um sonho delicioso a respeito, o qual, infelizmente, não pode ser publicado, pois seu pano de fundo, seu segundo sentido, desloca-se entre minha babá (mamãe) e minha mulher e, a rigor, não se pode submeter publicamente a própria esposa a essa espécie de recriminação [como recompensa] por todo o trabalho e os esforços dela. Dito de maneira genérica: o que de melhor se sabe não se pode dizer aos meninos. (FREUD, 1986, p.300 - itálico do autor)

No momento em que escreve um artigo para tornar pública sua teoria da sexualidade como fator etiológico das neuroses, Freud teve um sonho impublicável: este sonho modelo serviria como exemplar para demonstrar sua teoria da etiologia sexual das neuroses. É interessante constatar que nesta mesma carta, Freud afirmou que estava profundamente imerso "no livro dos sonhos” [A Interpretação dos Sonhos], escrevendo-o com fluência, e gostava da idéia de todas as ‘cabeças balançando’ por causa das indiscrições e ousadias que o livro conteria. (FREUD, 1986, p.299)

Comentando a importância do artigo “A sexualidade na etiologia das neurouroses”, o Editor Inglês, afirmou que a primeira parte do contém pouco mais que uma reafirmação das hipóteses já publicadas em periódico científico. No entanto, além ampliar o alcance público de sua teoria sobre os fatores emergentes da vida sexual na causação das neuroses, o artigo apresentou algo novo: uma abordagem de problemas sociológicos.

A crítica sem rodeios aqui feita à atitude da profissão médica em relação aos assuntos sexuais, particularmente à masturbação, ao uso de anticoncepcionais e às dificuldades da vida conjugal, prenuncia uma série de restrições posteriores de Freud às convenções sociais da civilização - começando com o artigo "Moral Sexual Civilizada", de 1908 e findando com o livro O Mal-estar na Civilização, de 1930. (In: FREUD, 1994, p.250)

\footnotetext{
${ }^{7}$ Literalmente, caramanchão, título de uma revista de assuntos domésticos cujo nome tornara proverbial por suas histórias sentimentais. A publicação desse artigo num periódico destinado ao público leigo em geral demonstra sua importância para tornar a psicanálise um conhecimento de domínio público que pudesse expandir os limites do saber médico. Freud pretendia assim, fazer com que sua teoria da causalidade sexual chegasse ao grande público. [A frase final em itálico é uma citação da cena 4 da parte I do Fausto de Goethe. Freud pelo visto adorava esta frase. No período em que estava escrevendo A Interpretação dos Sonhos, citou por diversas vezes esta frase em sua correspondência com Fliess].
} 
Freud iniciou seu artigo afirmando que "pesquisas exaustivas durante os últimos anos levaram-me a reconhecer que as causas mais imediatas e, para fins práticos, mais importantes de todos os casos de doença neurótica são encontrados em fatores emergentes da vida sexual”. (FREUD, 1994, p.251) Pretendia chamar atenção do público em geral e dos médicos em particular para a psicanálise e assim demonstrar a importância que suas asserções e para os benefícios práticos que poderiam extrair do conhecimento delas.

Reconheceu a dificuldade que esta empreitada implicava, pois era consenso entre os médicos e o público em geral que o tema da sexualidade não poderia ser abordado na relação entre o médico e o paciente. Por um "dever ético, o médico precisa manter-se afastado de toda a questão sexual”. (FREUD, 1994, p.252) Freud investiu sua crítica ao "puritanismo indigno” que serve apenas para esconder a ineficácia da prática médica no tratamento das neuroses. Denunciando o "puritanismo absurdo e o recato fora de lugar" que impede o médico de investigar os problemas sexuais nas neuroses, Freud afirmou:

se após um auto-exame honesto, [o médico] sentir que não possui o tato, a seriedade e a discrição necessários para interrogar pacientes neuróticos, e se estiver ciente de que as revelações de caráter sexual lhe provocariam arrepios lascivos, em vês de interesse científico, ele estará certo em evitar o tópico da etiologia das etiologias das neuroses. Tudo o que pedimos, além disso, é que se abstenha também de tratar pacientes nervosos. (FREUD, 1994, p.252)

Após uma longa descrição de cada uma das psiconeurores e das diferentes formas de tratamento disponível, Freud apresentou a psicanálise como uma técnica terapêutica fundada na compreensão de que os sintomas neuróticos são determinados por fatores emergentes da vida sexual. As vicissitudes dos sintomas neuróticos permitiram estabelecer que "a verdadeira etiologia só pode ser encontrada nas experiências infantis, e mais uma vez - exclusivamente - nas impressões referentes à vida sexual”. (FREUD, 1994, p.266) Esse argumento é de grande relevância para compreender que a hipótese da sexualidade infantil começava a ganhar força na elaboração teórica de Freud e na prática da psicanálise.

Ao demarcar a gênese da sexualidade infantil como fator determinante na produção dos sintomas neuróticos, Freud advertiu para o equívoco do discurso biológico que pretendia abordar a sexualidade como um processo de maturação das funções reprodutivas e, como tal, só apareceriam no período da puberdade. Erramos, disse Freud, ao ignorar 
inteiramente a vida sexual das crianças. A partir da experiência clínica da psicanálise é possível admitir que

as crianças são capazes de todas as atividades sexuais psíquicas, e também de muitas atividades somáticas. Assim como a totalidade do aparelho sexual humano não esta compreendida nos órgãos genitais externos e nas duas glândulas reprodutoras, também a vida sexual humana não começa na puberdade, como poderia aparecer a um exame superficial. (FREUD, 1994, p.266)

\section{CONCLUSÃO}

Em meio à Primeira Guerra Mundial, Freud lançou uma missiva ao movimento psicanalítico em estágio inicial. Ao publicar, em fevereiro de 1914, o primeiro registro da História do Movimento Psicanalítico, foi contundente ao reivindicar para si a autoria da psicanálise:

a psicanálise é criação minha; durante dez anos fui a única pessoa que se interessou por ela, e todo o desagrado que o novo fenômeno despertou em meus contemporâneos desabou sobre minha cabeça em forma de críticas (...) ninguém pode saber melhor do que eu o que é a psicanálise, em que ela difere de outras formas de investigação da vida mental, o que seria melhor chamar de outro nome qualquer. (FREUD, 1974, p. 16)

O objetivo de tal reivindicação é estabelecer a dissidência entre Jung e Adler. No entanto, a repercussão desse escrito atingiu a psiquiatria francesa. Na época, era lugar comum afirmar que a psicanálise de Freud era tributária das investigações de Charcot sobre a histeria e que a teoria do inconsciente era um plágio da tese da divisão da consciência de Janet. No entanto, deve-se ressaltar, como demonstrado acima, que as hipóteses de Charcot e de seu discípulo, Pierre Janet, estavam alicerçadas na teoria da hereditariedade e da degenerescência como agente etiológico da histeria. Para Freud,

Charcot pôde demonstrar, com o auxílio da hipnose, que os sintomas da histeria eram firmemente dependentes de certos pensamentos inconscientes. Janet atribuiu à histeria uma suposta incapacidade constitucional de manter reunidos processos mentais - uma incapacidade que levava a uma desintegração (dissociação) da vida mental. (FREUD, 1974, p. 6) 
Janet percorreu um caminho bem distinto daquele seguido por Freud. No entanto, julgou, apesar das evidências, que este último teria apenas aperfeiçoado sua teoria e obtido reconhecimento por ter se apropriado de suas concepções sobre a etiologia dos fenômenos histéricos.

No relato histórico de 1914, Freud afirmou que:

\begin{abstract}
Entre os países europeus, a França se tem mostrado, até agora, o menos receptivo à psicanálise, embora um trabalho de mérito em francês, da autoria de A. Maeder ${ }^{8}$ de Zurique tenha facilitado o acesso às teorias psicanalíticas. Os primeiros sinais de simpatia partiram das províncias: Morichau-Beauchmant ${ }^{9}$ (Poitiers) foi o primeiro francês a aderir publicamente à psicanálise. Régis e Hesnard ${ }^{10}$ (Bordéus) recentemente tentaram diluir os preconceitos dos seus compatriotas contra as novas idéias com uma minuciosa exposição, à qual, entretanto, nem sempre denota compreensão, sobretudo no tocante ao simbolismo. Na própria Paris, ainda parece reinar a conviç̧ão (a qual o próprio Janet deu eloqüente expressão no congresso de Londres em 1913) de que tudo de bom na psicanálise é repetição dos pontos de vista de Janet com insignificantes modificações e o mais não presta. (FREUD, 1974, p. 44)
\end{abstract}

O ponto de vista de Janet trouxe conseqüências decisivas para a psicanálise: Freud era considerado - por grande parcela dos psiquiatras da época - um plagiador. Em congressos posteriores, Janet foi questionado sobre os conhecimentos que afirmava serem de sua propriedade. Ao que parece, Janet não tinha uma compreensão da teoria do inconsciente, sobretudo porque ignorava o pressuposto clínico de Freud. A questão rendeu

\footnotetext{
${ }^{8}$ Alphonse Maeder, psiquiatra do grupo de Zurique - do qual fazia parte Jung - publicou nos Archives, em 1906, um texto introdutório à Interpretação dos Sonhos, que serviu como referência para os franceses travarem contato com a psicanálise de Freud. Ver ROUDINESCO, 1989, pp. 223-267.

9 "Foi com quatro artigos publicados por Pierre Ernest René Morichau-Beauchant (1873-1951) que a psicanálise fez sua entrada 'oficial' no solo pátrio. De fato, esse médico de Poitiers foi reconhecido por Freud como o primeiro francês a aderir abertamente à 'causa' (...) Sua posição abriu um rombo no contexto do antifreudismo francês. Ele foi o primeiro a inverter a problemática que dominava essa época e a criticar as teses de Janet à luz das de Freud. Reconheceu explicitamente o papel da sexualidade nos vínculos que uniam o paciente a seu médico (...) Leu os textos de Freud em alemão e fez surgir pela primeira vez o conceito de transferência...". (ROUDINESCO, 1989, p. 234)

${ }^{10}$ Emmanuel Régis foi professor de Hesnard e iniciou-o na psiquiatria, encarregando-o de estudar os trabalhos de Freud. "Ninguém pode contestar que se outorgue a Angelo Louis Marie Hesnard o título de primeiro pioneiro da psicanálise na França, mas sob a condição de acrescentar que ele foi o almirante de uma doutrina que arrancou do freudismo a essência de suas hipóteses, fazendo da sexualidade um lobisomem enganador". (ROUDINESCO, 1989, p. 272) Roudinesco sustenta o seguinte argumento: Hesnard procurou resolver os impasses Freud-Janet de forma simplista e ingênua, retirando do debate o pomo de discórdia: a sexualidade como fator etiológico das neuroses.
} 
incansáveis debates na década de 1920, sobretudo após a tradução para a língua francesa, em 1926, da obra A Interpretação de Sonhos.

Mesmo com todas as dificuldades encontradas para conquistar um lugar no movimento psiquiátrico francês, a psicanálise foi, cada vez mais, contagiando e conseguindo leitores originais e criativos. Se inicialmente cabia apenas a Freud o papel da pesquisa e da construção teórica, com o tempo, outros foram agregando-se ao trabalho e começaram a participar ativamente, principalmente no que se refere à divulgação e à transmissão da teoria. Muitos deles não pertenciam ao meio médico, outros, além de não pertencerem, tinham verdadeiro repúdio a tudo aquilo que representava a medicina psiquiátrica. 


\section{REFERÊNCIAS}

FREUD, S. Correspondência Completa de Sigmund Freud para Wilhelm Fliess (18871904). Editado por Jeffrey Moussaieff Masson. Rio de Janeiro: Imago, 1986.

. "História do Movimento Psicanalítico". In: Edição Standard Brasileira das Obras Psicológicas Completas de Sigmund Freud. Volume XIV. Rio de Janeiro: Imago, 1974.

. "Um estudo autobiográfico"; "A questão da análise leiga"; "Psicanálise". In:

Edição Standard Brasileira das Obras Psicológicas Completas de Sigmund Freud. Volume XX. Rio de Janeiro: Imago, 1976a.

. "Conferências Introdutórias sobre Psicanálise - XX e XXI" In: Edição Standard Brasileira das Obras Completas de Sigmund Freud. Volume XVI. Rio de Janeiro: Imago, 1976b.

. “Três Ensaios sobre a Teoria da Sexualidade” In: Edição Standard Brasileira das Obras Completas de Sigmund Freud. Volume VII. $2^{\text {a }}$ ed., Rio de Janeiro: Imago, 1989.

. "A hereditariedade e a etiologia das neuroses" e "A sexualidade na etiologia das neuroses”. In: Edição Standard Brasileira das Obras Completas de Sigmund Freud. Volume III. $3^{\text {a }}$ ed., Rio de Janeiro: Imago, 1994.

"Estudos sobre Histeria". In: Edição Standard Brasileira das Obras Completas de Sigmund Freud. Volume II. $3^{\text {a }}$ ed., Rio de Janeiro: Imago, 1995.

FOUCAULT, M. Doença Mental e Psicologia. Rio de Janeiro: Tempo Brasileiro, 1984.

. O Nascimento da Clínica. Trad. Roberto Machado. $4^{\text {a }}$ ed. Rio de Janeiro: Forense-Universitária, 1994.

. Ditos \& Escritos I - Problematização do Sujeito: psicologia, psiquiatria e psicanálise. Organização e seleção de textos: Manoel Barros da Motta.. Rio de Janeiro: Forense Universitária, 1999.

_. “O que é um autor?” In: Ditos \& Escritos III - Estética: Literatura e Pintura, Música e Cinema. Rio de Janeiro: Forense Universitária, 2001.

ROUDINESCO, E. História da Psicanálise na França - A Batalha dos Cem Anos. Volume 1: 1885-1939. Rio de Janeiro: Jorge Zahar, 1989.

SCHORSKE, C. Viena fin-de-sciècle - política e cultura. $2^{\mathrm{a}}$ ed. São Paulo: Companhia das Letras \& Editora Unicamp, 1988. 
